\title{
Effect of Postdefosition Annealing on Structure and Chemistry of the TiN Film/Steel Substrate Interfaces
}

\author{
A. Erdemir and C.C. Cheng \\ Materials and Components Technology Division \\ Argonne National Laboratory \\ Argonne IL 60439
}

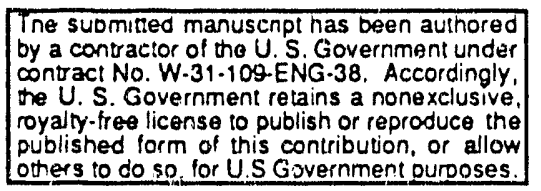

\section{DISCLAIMER}

This report was prepared as an account of work sponsored by an agency of the United States Government. Neither the United States Government nor any agency thereof, nor any of their employees, makes any warranty, express or implied, or assumes any legal liability or responsibility for the accuracy, completeness, or usefulness of any information, apparatus, product, or process disclosed, or represents that its use would not infringe privately owned rights. Reference herein to any specific commerciai product, process, or service by trade name, trademark, manufacturer, or otherwise dres not necessarily constitute or imply its endorsement, recom. mendation, or favoring by the United States Government or any agency thereof. The views and opinions of authors expressed herein do not necessarily state or reflect those of the United States Government or any agency thereof.

To be presented at the 37th Annual Symposium \& Topical Conferences Toronto, Canada

October $7-10,1990$ 


\title{
EFFECT OF POST-DEPOSITION ANNEALING ON STRUCTURE AND CHEMISTRY OF THE TIN FILM/STEEL SUBSTRATE INTERFACES ${ }^{\circ}$
}

\author{
A. Erdemir \\ Materials and Components Technology Division \\ Argonne National Laboratory \\ Argonne, IL 60439 \\ C. C. Cheng \\ Inland Steel Company \\ East Chicago, IN 46213
}

\section{ABSTRACT}

This study deals with solid-state phase transformations occurring at interfaces between a TiN film and an AISI M50 steel substrate during post-deposition annealing at 500 and $1000^{\circ} \mathrm{C}$. cross-sectional transmission electron microscopy (XTEM) was used to investigate the nature of phase transformations at these interfaces. The TiN films were ion plated onto M50 steel with an initial $\mathrm{Ti}$ underlayer at $100^{\circ} \mathrm{C}$. XTEM and electron-energy-loss spectroscopy of the interfaces indicated that the ion-plated Ti. underlayers transformed into a TiC phase during annealing at $500^{\circ} \mathrm{C}$ and into a $\mathrm{T} i(\mathrm{C}, \mathrm{N})$ phase during annealing at $1000^{\circ} \mathrm{C}$. In addition, the density of defects within grains was significantly reduced during annealing and the grains themselves became larger.

* This work was supported by the U.S. Department of Energy, Office of Transportation Materials, under Contract W-31-109-Eng-38. 


\section{INTRODUCTION}

Chemical and microstructural characteristics of thin films and film substrate interfaces have attracted considerable attention in recent years [1-3] because, these films originate in and intimately bond to the substrate materials across the interfaces. To characterize the interfaces, Auger electron spectroscopy (AES), Xray photoelectron spectroscopy (XPS), electron energy loss spectroscopy (EELS), and cross-sectional. transmission electron microscopy (XTEM) methods have been used extensively [1-4]. From the results of previous investigations, it appears that the nature of adhesion is strongly zelated to the extent of physicochemical interactions that occur at the film substrate interfaces [4-6]. To acrieve good correlation between adhesion strength and physicochemical interactions, it was demonstrated that one must use a combination of analytical tools (e.g., EELS, AES, XTEM) [4].

Because of their increasing importance in the metal-cutting and. forming, ball bearing, and electronics industries, TiN coatings and their interfaces have attracted more attention than other coating types. We have examined the effects of deposition temperature and initial $\mathrm{Ti}$ underlayers on the nucleation and growth mechanisms of TiN films on tool steel substrates [1-3]. Others have investigated the influence of intermediate layers and various surface pretreatments on adhesion between TiN films and a variety of steel substrates $[4-7]$. 
Among other factors, the deposition of $\mathrm{Ti}$ underlayers (typically $0.1 \mu \mathrm{m}$ thick) was proven to be beneficial to film adhesion and has become a routine practice in industrial TiN coating. Tt was thrught that such an underlayer could act as a glue that holds the TiN film and the underlying substrate together. Another argument was that since $T i$ is much tougher than $T i N$, it may help absorb some of the strain energy that may result from mismatches in thermal expansion coefficients and lattice parameters. Recent studies have demonstrated that these initial $\mathrm{Ti}$ underlayers may indeed be important in the nucleation and growth modes and thus in the adhesion of TiN coatings to commercial tool steel substrates [4-7]. Using a combination of analytical tools, we demonstrated that both deposition temperature [3] and substrate material [8] play najor roles in the chemical state of the $\mathrm{mi}$ underlayers. We found that these initial $\mathrm{Ti}$ underlayers transformed partially into a Tic phase during ion plating at $300^{\circ} \mathrm{C}$ and completely into a TiC phase during ion plating at $500^{\circ} \mathrm{C}[3]$. The carbon necessary for the synthesis of the Tic phase comes from the tool steel substrates which are generally rich in $c$.

Clearly, special emphasis has been placed on determining the effects of various aeposition parameters on the structural morphology and chemical characteristics of the films and film substrate interfaces. However, the influence of post-deposition annealing on the chemical and microstructural characteristics of the films and their interfaces has remained relatively unexplored. 
TiN coatings are generally subjected to harsh tribological environment.s often involving high temperatures. For eximple, during metal cutting and/or forming, the cutting edges of TiN-coated tool bits or inserts may reach quite high temperatures, mainly because of frictional heating. This may in turn increase the activation energy for solid-state diffusion of the atoms in the coating and tool materials and may eventually lead to phase transformations. In this paper, we report the solid-state phase transformations occurring at interfaces between a TiN film and an AISI M50 tool steel substrate during post-deposition annealing at 500 and $1000^{\circ} \mathrm{C}$. XTEM was used to investigate the nature of phase transformations at these interfaces. The TiN films were ion plated onto M50 steel with an initial $\mathrm{Ti}$ underlayer at $100^{\circ} \mathrm{C}$. 
EXPERIMENTAL

substrate Materials

The substrat:e material in this study was prepared from AISI M50 steel rods $(9.5 \mathrm{~mm}$ in diameter) by slicing them into 4 -mm-thick disks. The chemical composition (in wt.\%) of this steel was $c$ : $0.84, \mathrm{Cr}: 4.16, \mathrm{Mo}: 4.18, \mathrm{~V}: 0.99, \mathrm{Mn}: 0.29, \mathrm{Si}: 0.21, \mathrm{~S}: 0.004, \mathrm{P}:$ 0.005 , with the balance being $\mathrm{Fe}$.

one side of each sliced disk was ground and polished progressively to give a final surface finish of approximately $0.05 \mu m$ centerline-average. The disks were ultrasonically cleaned in acetone, ilethanol, and distilled water before being ion plated with TiN.

Ion plating of TiN

The TiN coatings were deposited on the polished side of the substrate disks in an ion-plating system equipped with a hollow cathode discharge (HCD) electron beam gun that served two important purposes: (a) intensification of glow-discharge plasma around the substrate holder and (b) evaporation of the pure $\mathrm{Ti}$ source from $\mathrm{a}$ water-cooled crucible. Before ion plating, adsorbed contaminants were removed from the substrate surface by creating an argon glow discharge plasma around the specimens for $10 \mathrm{~min}$. The substrates 
were heated to $100^{\circ} \mathrm{C}$ by radiant heaters. Finally, the HCD gun was energized to evaporate the pure $\mathrm{Ti}$ into the argon plasma, which was created and sustained by applying a bias voltage of $100 \mathrm{~V}$ negative DC to the substrate holder while chamber pressure was maintained at about $0.11 \mathrm{~Pa}$. A 100-nm thick pure Ti layer was deposited first on the substrate. Nitrogen gas was then admitted into the deposition chamber to synthesize the TiN phase on top of the initial Ti layer. Total thickness of the resultant films was approximately $2 \mu m$. A more detailed description of the ion-plating system and associated procedures can be found in Ref. 9 .

Following ion plating, a few of the coated specimens were subjected to post-deposition annealing at $500^{\circ}$ and $1000^{\circ} \mathrm{C}$ for $45 \mathrm{~min}$. A highvacuum furnace, capable of maintaining a vacuum level of better than $10^{-4} \mathrm{~Pa}$, was used.

Cross-sectional Transmission Electron Microscopy

Thin foils for XTEM examination were prepared by progressively thinning the cross-sectioned samples with dimpling and ion milling machines. First, the TiN-coated substrates were cut into rectangular slabs, typically $2 \times 1 \mathrm{~mm}$. The TiN-coated sides of these slabs were glued together with epoxy and allowed to dry. They were then placed in a $3-m m$-diameter stainless steel tube filled with a conductive epoxy. Several disks of $0.5 \mathrm{~mm}$ thickness were cut 
from this tube and progressively thinned by mechanical grinding. The thickness of the disk center was further reduced with a dimpling machine to about $20 \mu \mathrm{m}$. Thinning of the central portion of the samples was continued with an ion beam milling machine that incorporated two ion-beam sources, each operating at $6 \mathrm{kV}$ and an ion current of $2000 \mu \mathrm{A}$. A Ta mask was used to avoid preferential milling of either the steel or the TiN side. The Ta mask was positioned to cover at least half of the specimen surface, which was initially milled at an angle of $15^{\circ}$ for about $3 \mathrm{~h}$, followed by further milling at a reduced angle of $12.5^{\circ}$ for another 3 to $4 \mathrm{~h}$. our experience has shown that by following these steps, one can successfully obtain a thin foil consisting of both the film and substrate sides of the original samples and is transparent to an electron beam. A more detailed description of the preparation procedures is given in Refs. 1 and 2 .

The XTEM examination of the thin foils was conducted in a Philips EM 420 analytical electron microscope incorporating a Gatan EEIS and. an energy-dispersive X-ray (EDAX 9900) data acquisition system. The microscope was operated at $120 \mathrm{kV}$. 
RESULTS AND DISCUSSION

\section{As-Deposited TiN Films}

Figure la is an XTEM micrograph of the as-deposited TiN film. As is clear from this micrograph, the initially deposited $\mathrm{Ti}$ underlayer is unique and is separated from the TiN film and the M50 steel by distinct boundaries. Convergent beam electron diffraction (see pattern in inset of Fig. 1a), together with the EELS spectrum (see Fig. Ib) reveals that the underlayer retains its original crystalline structure, i.e., $u-T i$. The presence of some $N$ and $C$ atoms within this layer cannot be ruled out. However, as suggested by the diffraction pattern and the EELS spectrum, the $N$ and $C$ concentrations must have been too low to be deterted by EEIS and/or to trigger phase changes. Accorcing to the Ti-N phase diagram [10], atomic $N$ can dissolve in $e-T i$ up to about 22 at.\% at room temperature without causing phase transformation. Likewise, c can also dissolve in e-Ti as an interstitial species.

As for solia-state interactions between substrate and Ti atoms, wie believe that solid-state interdiffusion and chemical reaction rates were inadequate at $100^{\circ} \mathrm{C}$. As a result, the initially depo: ed Ti layer remained chemically undisturbed. However, because of the intense ionic/atomic bombardnent, the surface mobility of the $\mathrm{Ti}$ atoms was relatively high. Therefore, the Ti atoms could fill in the gaps and low-atomic-density areas and thus suppress columnar 
growth. In previous studies, we demonstrated that at higher ionplating temperatures, e.g., 300 and $500^{\circ} \mathrm{C}$, the initial $\mathrm{Ti}$ underlayers transformed partially or completely into TiC, depending on deposition temperature $[1-4]$. The $C$ necessary for phase transformation came from the c-rich tool steel substrates.

Morphologically, the Ti phase consists of large and some small grains. At the top of the substrate surface is a zone about $10 \mathrm{~nm}$ thick with no detectable grain boundaries. Based on this observation, we believe that because of the relatively low thermal activation for bulk diffusion and chemical reaction - but also due to a fairiy high surface diffusion capability for depositing $T i$ atoms (mainly because of the continuous ionic/atomic bombarciment) Ti atoms conciense first on the surface in a layer-by-layer growth mode, thereby forming a zone with no apparent grain boundaries [3]. However, as the coating thickons, the Ti atoms tend to regroup themselves and form equiaxed grains, as seen in the center of the Ti underlayer (see Fig. 1a). This behavior is known as the. Stranski-Krastanuv growth mode [11].

As for the TiN film grown atop the $\mathrm{Ti}$ underlayer, the grain morphology is the dense columnar type. The boundaries between stesI substrate and $\mathrm{Ti}$ underlayer, and between $\mathrm{Ti}$ underlayer and $\mathrm{TiN}$ phase, are rather discrete. Unlike magnetron-sputtered TiN films $[2,12]$, the ion-plated TiN films do not appear to contain intercolumnar pores and/or void networks. 
TiN Film Post-Annealed at $500^{\circ} \mathrm{C}$

The XTEM micrograph in Fig. 2 a shows the microstructure of a TiN film subjected to post-annealing at $500^{\circ} \mathrm{C}$. It is clear that marked changes occur in both the chemical and structural states of the films ind interfaces during post-annealing.

First, from the convergent beam electron diffraction pattern (inset in Fig. 2a), we found that the initial $\mathrm{Ti}$ underlayer had t-ansformed into a phase exhibiting a B1-type NaCl crystal structure. Both $\mathrm{TiC}$ and $\mathrm{TiN}$ are known to possess this type of crystal structure. Their lattice parameters are also very close, i.e., $4.239 \dot{A}$ for $\operatorname{TiN}$ and $4.327 \dot{A}$ for TiC. Therefore based on diffraction pattern alone, it was difficult to ascertain whether the interface was transformed into a TiN or a TiC phase. With the aid of EELS, we found that $\mathrm{Ti}$ and $\mathrm{C}$ were the most abundant species in this region (see Fig. 2b). Based on these findings, we concluded that the Ti underlayer was transeormed into TiC.

Second, as shown in Fig. 2a, the boundaries separating (a) the substrate from the original underlayer and (b) the underlayer from the TiN phise are not as clearly defined as those seen in the asdeposited TiN films. Third, the grains within the underlayer are well-defined and have distinct boundaries. The grains are equiaxea, with sizes in the order of $100 \mathrm{~nm}$. A zone composed of very fine grains ( 5 to $10 \mathrm{~nm}$ across) is also noticeable near the substrate 
surface. Finally, although still columnar in nature, this original grain morphology of the TiN phase was somewhat distorted; column diameter becomes larger after post-annealing. Furthermore, the columnar grains shown in Fig. 2 a exhibit a lower defect density than that of the original grains.

For the phase transformation during post-annealing at $500^{\circ} \mathrm{C}$, we propose the following explanation. We believe that at this relatively high temperature, activation energy for bulk diffusion and chemical reaction increases for the atomic species constituting the coating and substrate materials. In particular, those species with higher diffusion coefficients can migrate with relative ease. Among all the atoms within the film/substrate system, c enjoys the highest diffusion coefficient at $500^{\circ} \mathrm{C}$ in a-Ti [13]. Therefore, having migrated across the interface, it can accumulate within the underlayer Ti, which incidentally has a high chemical affinity for C. Accoraing to a recent paper by Bergner [13], C at $500^{\circ} \mathrm{C}$ has a diffusion coefficient nearly three orders of magnitude higher than. the next candidate atom $(N)$ in the system. The M50 steel consists of 0.85 wt.\% $C_{i}$ thezefore, we believe that the phass transformation, i.e., the synthesis of TiC, during post-annealing at $500^{\circ} \mathrm{C}$ was controlled by the $\mathrm{C}$ atoms from the steel substrate. In a series of previous studies, we observed that similar phase transformations can also occur at interfaces between $\mathrm{Ti}$ underlayers and steel substrates when ion plating was performed at $500^{\circ} \mathrm{C}[1,3]$. 
Diffusion of $N$ from the top layer of $T i N$ into the $T i$ underlayer is thought to be highly urlikely, because most of the $\mathrm{N}$ atoms are already chemically bound to Ti. Thermodynamically, TiN is more stable than TiC and thus cannot be oxidized further by TiC [14]. Nevertheless, the presence of complex phases comprising both $N$ and C atoms, especially near the interphase boundary between TiN and TiC and between Tic and steel cannot be ruled out. The EELs systed used in our study had a relatively large beam size (about $40 \mathrm{~m}$ in diameter). This inade it difficult to analyze the chemical nature of interphase boundaries at a much Iiner scale. High-resolution EEIS may be helpful in determining the true chemical states of these interfaces.

\section{TiN Film Post-Annealed as $1000^{\circ} \mathrm{C}$}

The XIEM micrograph in Fig. 3 reveals the extent of solid-state phase transformations at interfaces during post-annealing at $1000^{\circ} \mathrm{C}$. Convergent-beam electron diffraction, together with an E⿰IS spectrum (inset) suggested that the initial $\mathrm{Ti}$ underlayer had transformed into two phases: TiN and TiC. The presence of other phases incorporating $F e, C r$, or Mo could not be ascertained witi EELS, mainly because of the large beam size used.

The grains of the newly formed phases are equiaxed and someriat smaller than those formed during post-annealing at $500^{\circ} \mathrm{C}$. Again, the grains near the Mo substrate are generally smaller than those near the center of the transformed layer. The interface between the 
transformed layer and the M50 substrate appears sharp but has a ragged shape.

As is evident from Fig. 3, the columnar nature of the original grains within the TiN phase is preserved tven after post-annealing at $1000^{\circ} \mathrm{C}$ however, the density of defects within the grains is significantly reduced and the columnar grains increase substantially in diameter during post-annealing.

Basfod on the evidence provided in Fig. 3, we propose the following interpretation for the ciserved phase transformations at $1000^{\circ} \mathrm{C}$. Ahove $882^{\circ} \mathrm{C}$, the e-Ti phase transtorms into the B-Ti phase and the diffusion coefficients of $C$ and $N$ increase dramatically. Eor example, the diffusion coefficient of $N$ is approsimately five orders of magnitude highe in B-Ti at $1000^{\circ} \mathrm{C}$ than in e-Ti at $500^{\circ} \mathrm{C}$. The diffusion coefficient of $C$ also increases but not as dramatically as that of $\mathrm{N}$. Compared to that in e-Ti at $500^{\circ} \mathrm{C}$, the diffusion coefficient $c=C$ is nearly three orders of magnitude higher in B-Ti at $1000^{\circ} \mathrm{C}$. Hence, the difference in diffusior. coefficient between $C$ and i narrows to about one order of magnituae when the post-annealing temperature is raised to $1000^{\circ} \mathrm{C}$. Consequently, along with $C$, some $N$ atoms can also ciffuse into the Ti underlayer at $1000^{\circ} \mathrm{C}$ and particisaze in the phase transformation.

We believe that at $1000^{\circ} \mathrm{C}$, the extent and nature of the solid-state 
phase transformations at interfaces are governed by the solid-state diffusion rates and chemical reaction rates of participating atoms, i.e., C, N, and Ti. Eecause of their significantly higher diffusion coefficient, $C$ atoms diffuse faster into the $\mathrm{Ti}$ underlayer than do $\mathrm{N}$ atoms. However, because of a more negative standard heat of reaction with $\mathrm{Ti}$, the $\mathrm{N}$ atoms react more readily with $\mathrm{Ti}$ than do $\mathrm{C}$ atoms $\left(e . g .\right.$, at $1000^{\circ} \mathrm{C}$, the standard heat of reaction for $\mathrm{N}$ and $\mathrm{Ti}$ to form $\mathrm{TiN}$ is about $-80,700 \mathrm{cal} / \mathrm{mole}$ and for $\mathrm{C}$ and $\mathrm{Ti}$ to form $\mathrm{TiC}$ is about $-44,970$ cal/mole). Furthermore, there is a distinct possibiliti that while the Ti atoms may have initially reacted with fast-diffusing $C$ atoms and already turned into TiC, a chemical reaction between $\mathrm{N}$ and $\mathrm{TiC}$ may have taken place as $\mathrm{N}$ atoms besome av ilable and TiN may have formed as a result of a secondazy prase tzansformation. At $1000^{\circ} \mathrm{C}$, the heat of reaction favors formation of TiN, not TiC. of course, there are some limiting factors. First, for such a secondary phase transformation to take place, $N$ atoms must be readily available within the underlayer; therefore, there are kinetic constraints. Second, most $N$ atoms are chemically bound. to $\mathrm{Ti}$ and are not readily available. Thermodynamically, tne Iiberation of $N$ from $T i$ is thought to be quite difficult. we therefore, believe that the $N$ atoms participating in the prase transformation of the interface region were those of the interstitial solution type, not the reacted type.

Because of the dynamic nature of the kinetic and themodynamic events at such interfaces during post-deposition annealiny, it is 
difficult to obtain a clear understanding of the mechanisms involved in the solid-state phase transformations explored in this study. However, the data presented provide some insight and are consistent with the thermodynamic and kinetic constraints imposed on each c.tomic species at the annealing temperatures used in this study.

\section{CONCLUSIONS}

(1) The extent and nature of the solid-state phase transformations at interfaces are subject to particular kinetic and thermodynamic constraints imposed on $C, N$, and $T i$ at each post-annealing temperature.

(2) The ion-plated Ti underlayer transforms into a TiC phase during post-annealing at $500^{\circ} \mathrm{C}$. The $\mathrm{C}$ atoms necessary for phase transformation come from the M50 substrate.

(3) The ion-plated $\mathrm{Ti}$ underlayer transforms into TiC and TiN phases during annealing at $1000^{\circ} \mathrm{C}$. The $\mathrm{N}$ atoms necessary for the synthesis of TiN come from the TiN film.

(4) The density of defects within grains is significantly reduced during post-annealing and the grains become larger. 
ACRNOWLEDGMENT

This work was supported by the U.S. Department of Energy, office of Transportation Materials, under Contract W-31-109-Eng-38. 


\section{REFERENCES}

1. A. Erdemir and C. C. Cheng, Ultramicroscopy, 29, 266 (1969).

2. A. Erdemir and C. C. Cheng, J. Vac. Sci. Technol., A.7, 2486 $(1989)$.

3. A. Erdemir and C. C. Cheng, Surf. Coat. Technol., 41, 285 $(1990)$.

4. C. C. Cheng, A. Erdemir, and G. R. Fenske, Surf. Coat. Technol., $39 / 40,365$ (1989).

5. U. Helmersson, B. O. Johansson, J.-E. Sundgren H.T. G. Hentzell, and P. Billgren, J. Vac. Sci. Technol., A3, 308 (1985).

6. D. S. Rickerby and R. B. Newbery, Proc. IPAT 87, (CEP Consultants, Brighton, Edinburgh, UK, 1987), p. 224.

7. M. Van Stappen, B. Malliet, L. De Schepper, I. M. Staj.s, J. P. Celis, and J.R. Roos, Surf. Eng., 5, 305 (1989).

E. A. Erdemir and C. C. Cheng, Ultzamicroscopy (in press, 1sפ0)

9. A. Erdemir, W. B. Carter, and R. F. Hochman, Surface Modification Technologies II, Eds. T. S. Sudarshan and D. G. Ehat, TMS Conf. Proc., Warrenciale, PA, 261 (1989).

10. H. A. Wriedt and I. I. Murray, Bull. Alloy Phase Diag., $\varepsilon, 37 \varepsilon$ $(1987)$.

11. J. A. Venables, D. G. T. Spilier, and M. Handbucken, Rep. Erog. Phys., 47, 399 (1984).

12. C. Ernsberger, A. J. Perry, I. P. Lehman, A. E. Miller, A. R. Pelton, and B. W. Dabzowski, Surf. Coat. Technol., 36, 605 (19ob).

13. D. Bergner, Diffusion of Metals and Allovs, series $\ddot{F} 7$, Eis. F. J. Kedves and D. I. Beke, (Trans Tech Publications, Zurich, Switzerland 1983), p. 223.

14. C. E. Wicks and F. E. Block, Thermodvnamic Properties of 63 Elements-Their oxides, Halides, Carbides, and Nitrides, U.S. Sureau of Mines, Bulletin $\# 605,123$ (1963). 
FIGURE CAPTIONS:

Fig. 1. (a) XTEM micrograph (inset shows convergent beam electron diffraction pattern) and (b) EELS spectrum of interfacial region of TiN film ion plated at $100^{\circ} \mathrm{C}$ on $\mathrm{M} 50$ steel substrate with $\mathrm{Ti}$ underlayer.

Fig. 2. (a) XTEM micrograph (inset shows convergent beam electron diffraction pattern) and (1) EELS spectrum of interfacial region of TiN following post-annealing at $500^{\circ} \mathrm{C}$.

Fig. 3. XTEM micrograph and EELS spectrum of the interfacial region of TiN film following post-annealing at $1000^{\circ} \mathrm{C}$. 

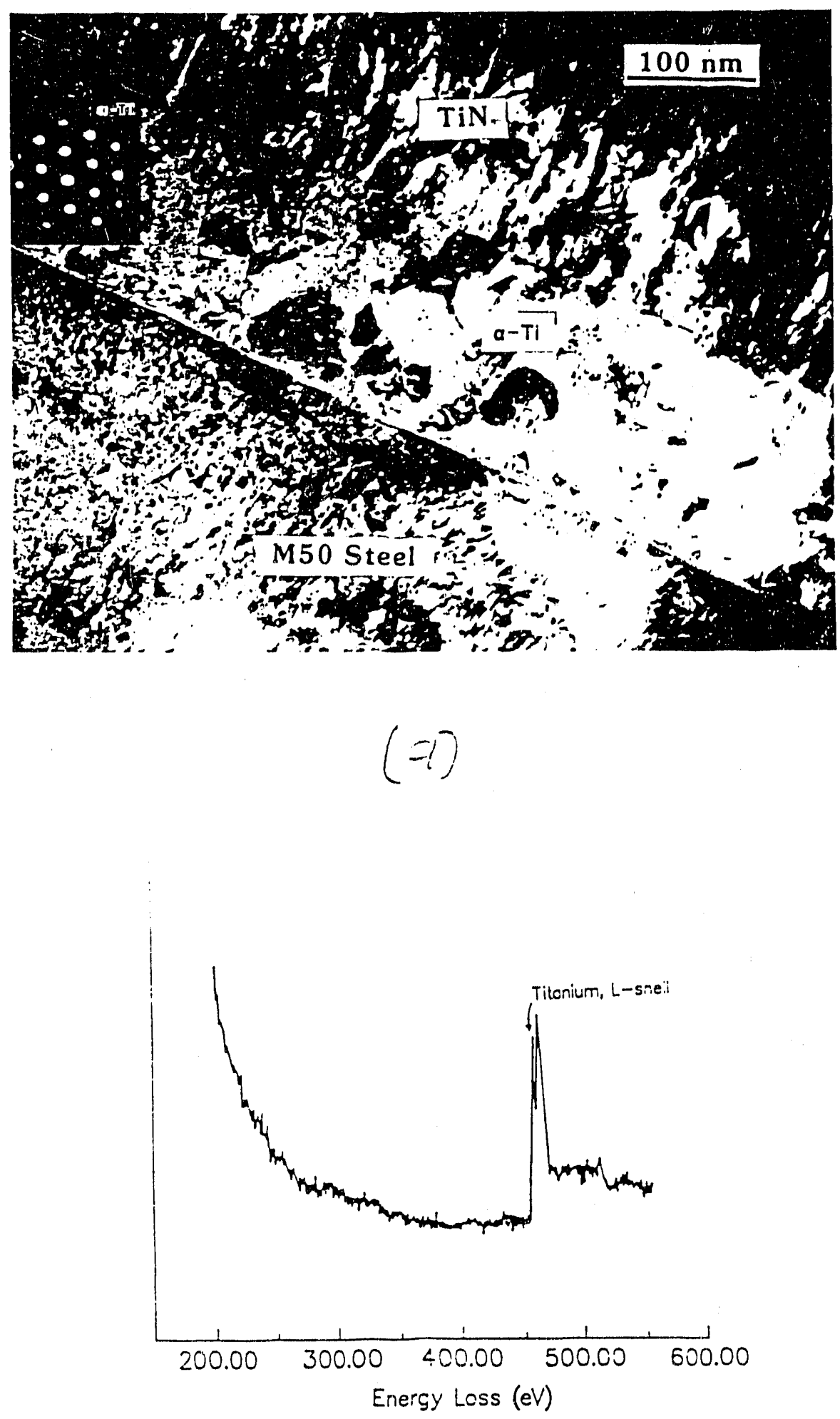

(c)

Fig. 1 


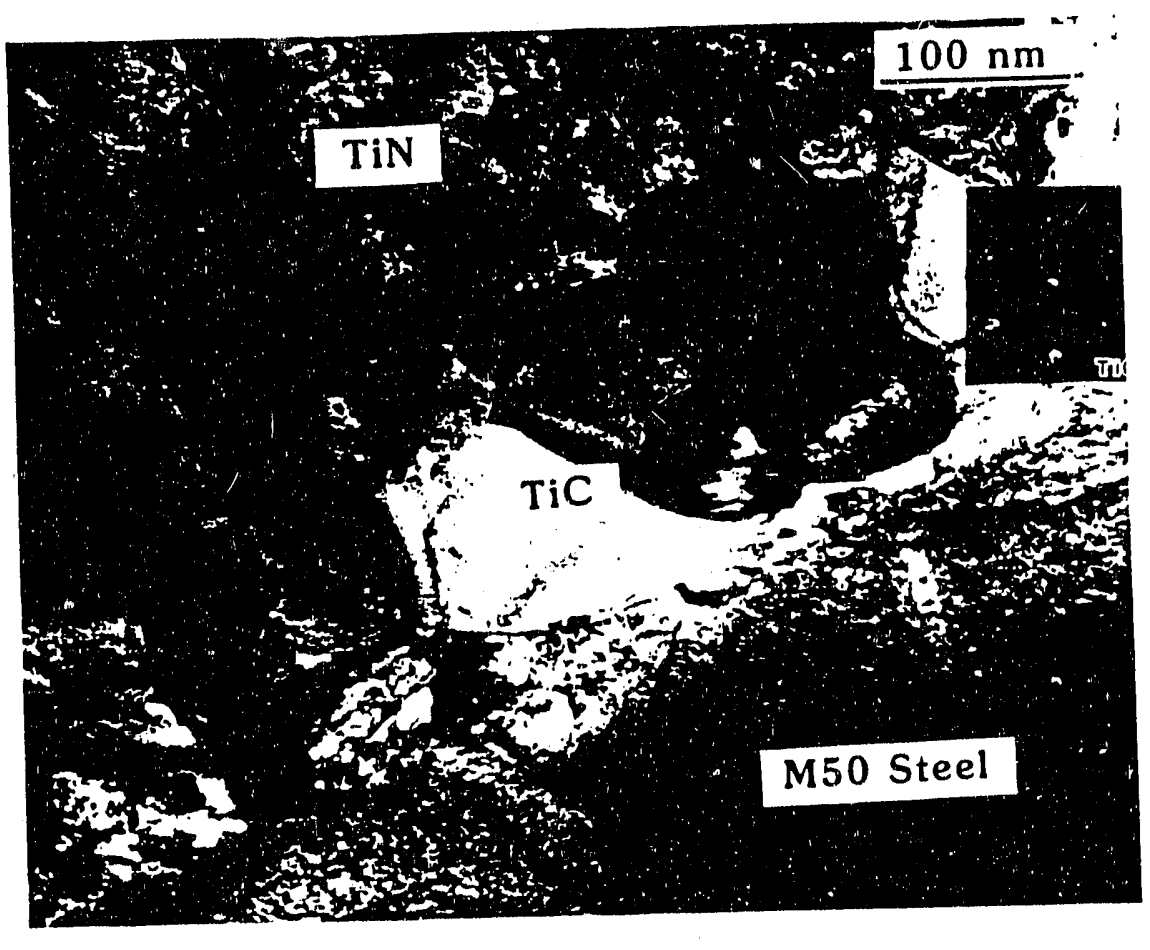

(a)

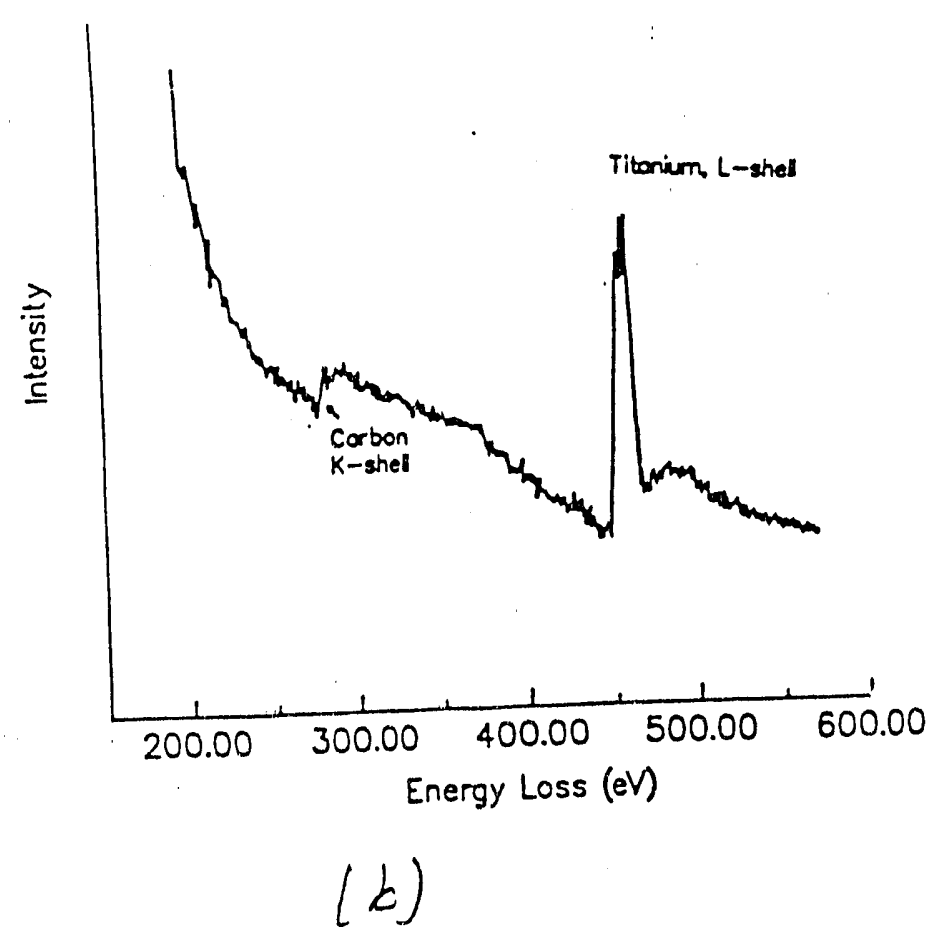

Fig. 2 


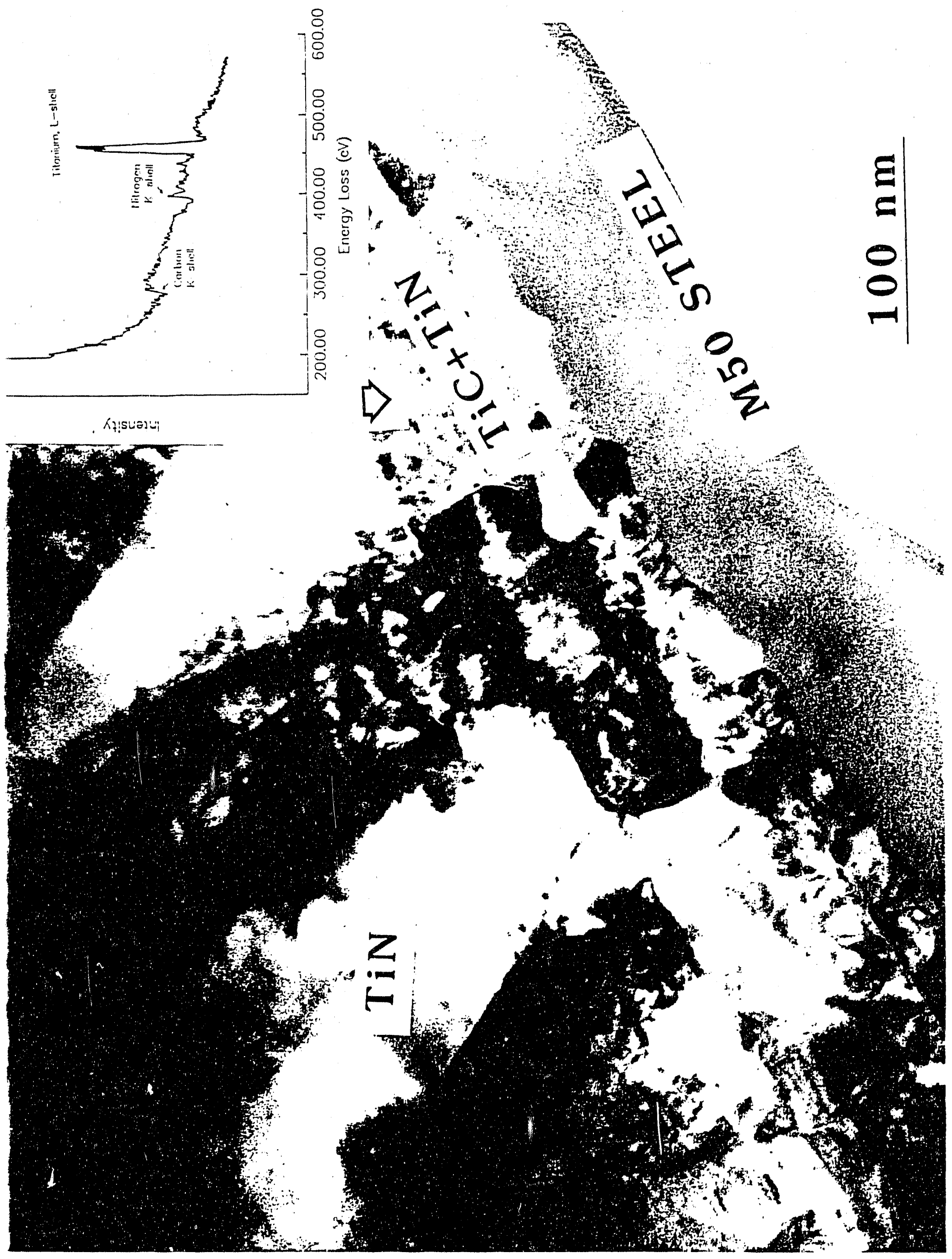



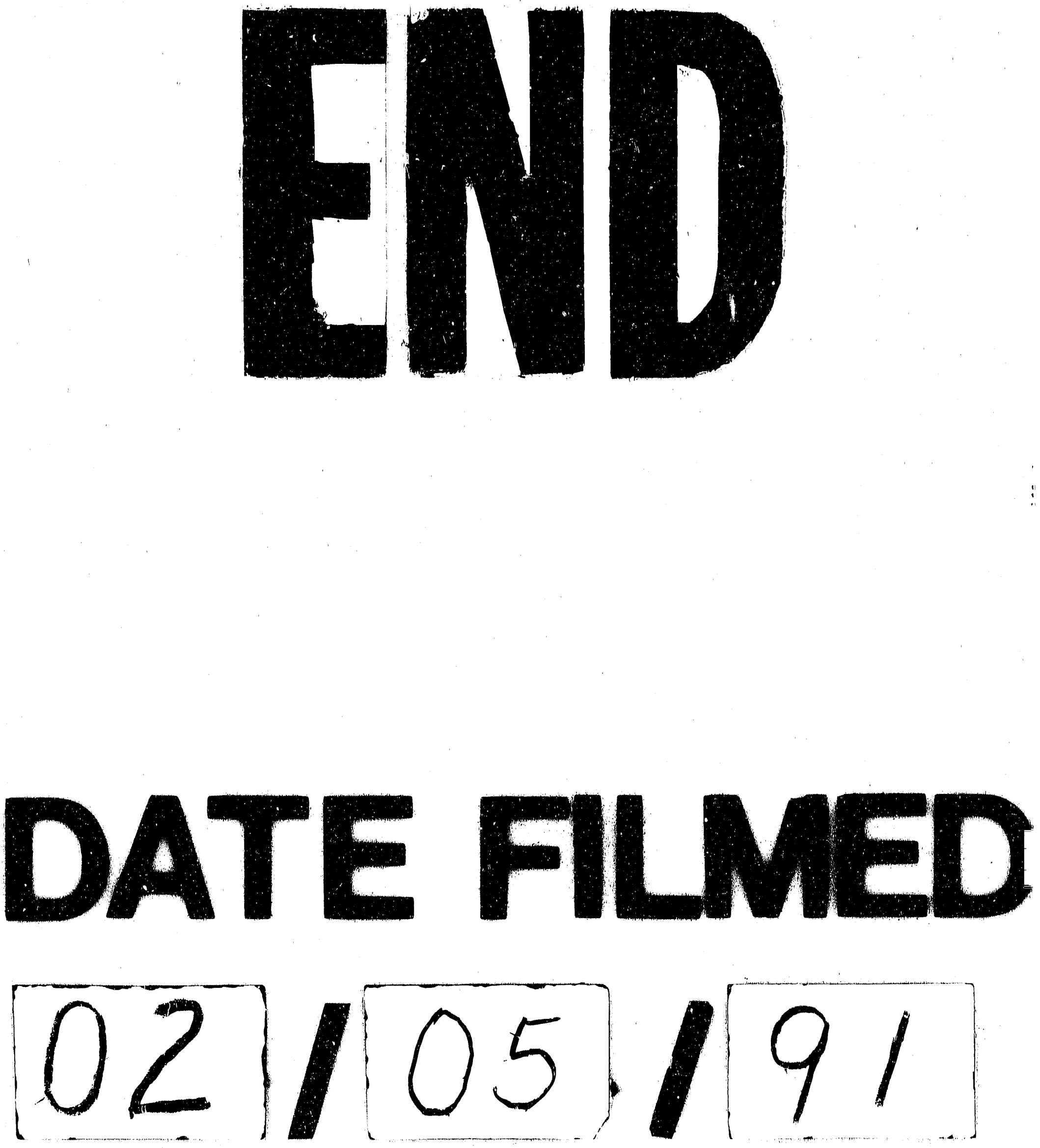
